Bundesgesundheitsbl 2021 · 64:1559-1569 https://doi.org/10.1007/s00103-021-03445-3 Eingegangen: 31 . Mai 2021

Angenommen: 30 . September 2021 Online publiziert: 27. Oktober 2021 (c) Springer-Verlag GmbH Deutschland, ein Teil von Springer Nature 2021

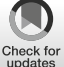

Ursel Heudorf · René Gottschalk · Antoni Walczok · Peter Tinnemann · Katrin Steul

Gesundheitsamt Frankfurt am Main, Frankfurt, Deutschland

\title{
Kinder in der COVID-19 Pandemie und der Öffentliche Gesundheitsdienst (ÖGD)
}

\section{Daten und Überlegungen aus Frankfurt am Main}

\section{Hintergrund}

Zur Eindämmung der COVID-19-Pandemie wurden weltweit zahlreiche Maßnahmen ergriffen. In Deutschland wurde am 22.03.2020 der erste sog. Lockdown ausgerufen: Nur noch Geschäfte für den alltäglichen Bedarf blieben geöffnet. Gaststätten, Hotels, kulturelle Einrichtungen wie Museen, Theater, aber auch Außenanlagen wie botanische Gärten, Parks und Spielplätze wurden geschlossen [1]. Die Schließung betraf auch Schulen und Kitas, wobei ein Notbetrieb für Kinder aufrechterhalten wurde, deren Eltern in der kritischen Infrastruktur beschäftigt sind. Ab Mai 2020 konnten Schulen und Kitas unter strengen Abstands- und Hygieneauflagen wieder öffnen. Das Schuljahr 2020/2021 startete im sog. Präsenzunterricht unter COVID19-Bedingungen, d.h. mit AHA + L-Regeln (Abstand, Hygiene, Alltagsmaske und Lüften), auch der Betrieb der Kitas begann mit strengen Hygieneregeln, wie kleinen Gruppengrößen, Abstand, Lüften. Mit zunehmender Inzidenz in der Gesamtbevölkerung ab Oktober 2020 wurden zum 01.11.2020 wieder Gaststätten, Theater und andere kulturelle Einrichtungen geschlossen (sog. Lockdown light), ab 17.12.2020 wurde ein erneuter Lockdown mit Schließung der Schulen und Kindergemeinschaftseinrichtungen, umfangreichen Kontaktbeschränkungen sowie Ausgangssperren verfügt. In Hessen konnten ab März 2021 zumindest die Kinder bis zur
Klasse 6 und der Abschlussklassen die Schule wieder besuchen, zunächst nur im Wechselunterricht. Nach den Osterferien wurde diese Möglichkeit mit einer Antigentestpflicht (zweimal pro Woche) verknüpft. Infolge der sog. Bundesnotbremse [2] musste in Gemeinden mit einer 7-Tage-Inzidenz von über 165/100.000 der Präsenzunterricht wieder ausgesetzt werden. Bis zum Ende des Schuljahres 2020/2021 war jedoch in allen Bundesländern ein normaler Schul- und Kitabetrieb unter COVID19-Bedingungen wieder gewährleistet.

Diese staatlichen Maßnahmen hatten erhebliche Auswirkungen auf das gesellschaftliche Leben insgesamt. Insbesondere waren aber Kinder und Jugendliche und deren Entwicklungsmöglichkeiten durch geschlossene Schulen, ausgesetzten Präsenzunterricht, gesperrte Spielplätze und Kontaktverbote stark betroffen. Die Deutsche Gesellschaft für Krankenhaushygiene und die pädiatrischen Fachgesellschaften haben wiederholt auf die zu erwartenden Kollateralschäden dieser Infektionsschutzmaßnahmen hingewiesen und eine baldige Wiederöffnung der Schulen und Kitas gefordert [3-9]. Auch vor zunehmenden Kinderschutzfällen (z. B. Kindesvernachlässigung oder -misshandlung) wurde gewarnt [10].

Für die Gesundheitsämter ergaben sich durch die Pandemie ebenfalls erhebliche Änderungen. Um die Flut der SARS$\mathrm{CoV}$-2-Meldungen zeitnah abarbeiten zu können, wurden die meisten Leistungen der Ämter eingestellt und die Mitarbeiter für die Meldepflichtbearbeitung und Kontaktpersonennachverfolgung eingesetzt. Sehr bald wurden zusätzlich Beschäftigte aus anderen Ämtern, Studenten (Medis4ÖGD), sog. Containmentscouts und ab Sommer 2020 die Bundeswehr für die Fallermittlung und Kontaktpersonennachverfolgung eingesetzt. Viele Gesundheitsämter änderten ihre Organisationsstruktur. In Frankfurt am Main (FFM) beispielsweise wurden u. a. Teams für Krankenhäuser, Altenpflegeheime, soziale Einrichtungen und Schulen gebildet, die Ansprechpartner für diese Einrichtungen waren, dort wichtige Beratungsaufgaben übernahmen, die Fall- und Kontaktpersonenermittlung im Einrichtungsbezug durchführten und bei Bedarf Testserien veranlassten und begleiteten $[11,12]$. Viele wichtige - und selbst gesetzlich mandatierte - Aufgaben der Gesundheitsämter konnten nicht mehr wahrgenommen werden, auch viele präventive Aufgaben des Kinder- und Jugendgesundheitsdiensts (KJGD) - in FFM ebenso wie in anderen Gesundheitsämtern [13].

Nachfolgend sollen die Daten der dem Gesundheitsamt FFM gemeldeten Kinder mit SARS-CoV-2-Nachweisen, die Daten der Untersuchungen von Kontaktpersonen in Schulen und Kitas sowie die Ergebnisse der ab April 2021 für Schüler verpflichtenden Antigenschnelltests vorgestellt und vor dem Hintergrund der Schließungen bzw. Einschränkungen der Schul- und Freizeitangebote einschließ- 


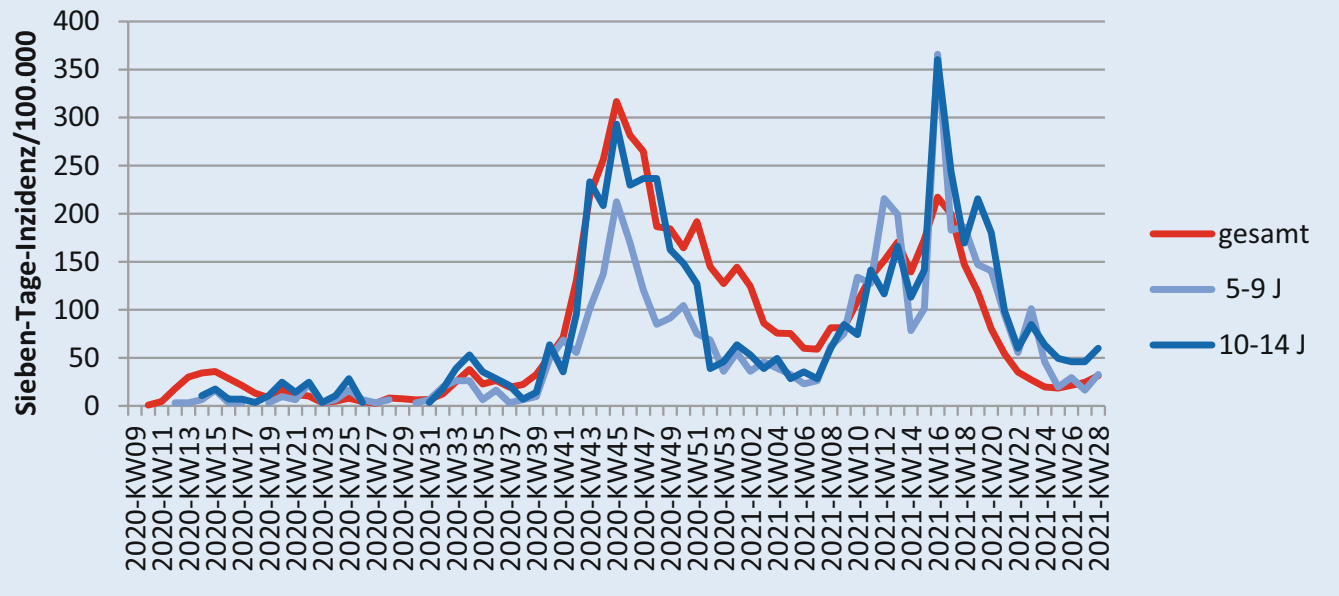

Abb. $1<$ SARS-CoV-2Meldungen über die Kalenderwochen. 7-TageInzidenzen bei Kindern der Altersgruppen 5-9 und 10-14 Jahre sowie in der Gesamtbevölkerung in Frankfurt am Main von KW 10/2020 bis KW 28/2021. (Eigene Abbildung)

lich der Sport- und Vereinssportangebote diskutiert werden. Dabei wird hinterfragt, ob die Balance zwischen Infektionsschutz und Entwicklungsmöglichkeiten der Kinder [14] beachtet wurde und ob die Gesundheitsämter, und hier insbesondere die Kinder- und Jugendgesundheitsdienste, ihre vielfältigen präventiven Aufgaben für die Kinder [15, 16] noch ausreichend wahrnehmen konnten.

\section{Material und Methode}

Mittels einer SURVStat-Abfrage für den Zeitraum Kalenderwoche KW 10/2020 bis KW 28/2021 wurden die Meldedaten aus FFM für die Gesamtbevölkerung ( $n=747.848$ Einwohner) sowie speziell für die Altersgruppen 0-4 Jahre $(n=40.888), 5-9$ Jahre $(n=35.034)$ und 10-14 Jahre $(n=32.232)$ gewonnen [17]. Die Symptome wurden mit einer SURVNet-Abfrage ermittelt. Nach Beginn des Schuljahres 2020/2021 wurden alle SARS-CoV-2- positiv gemeldeten Kinder im Hinblick auf Anwesenheit in der Einrichtung und auf mögliche Kontaktpersonen (KP) gemäß der Empfehlung des Robert Koch-Instituts (RKI; [18]) erfasst. Von KW 34/2020 bis KW 28/2021 wurden in Frankfurt am Main insgesamt 3594 Kinder im Alter von 0 bis 14 Jahren gemeldet, das sind 9,5\% aller in diesem Zeitraum mit SARS-CoV-2 Gemeldeten, wobei der Anteil der Kinder bis 14 Jahre an der Gesamtbevölkerung 14,5\% beträgt.

Im Auftrag des Gesundheitsamtes entnahmen die Hilfsorganisationen Deut- sches Rotes Kreuz (DRK) und ArbeiterSamariter-Bund (ASB) bei Kontaktpersonen auf freiwilliger Basis tiefe NasenRachen-Abstriche, die dann in 2 Laboratorien (Bioscientia Institut für medizinische Diagnostik sowie Institut des DRKBlutspendedienstes in FFM) mittels Polymerasekettenreaktion (PCR; [19]) auf SARS-CoV-2 untersucht wurden. In Kitas wurden die KP der jeweiligen Indexperson (Person, von der das vermutete Übertragungsrisiko ausgeht) bis zum Ergebnis des PCR-Tests in Quarantäne geschickt, in den Schulen konnten sie mit Mund-Nasen-Schutz weiterhin am Schulbetrieb teilnehmen. Die PCR-Daten wurden in einer Excel-Datei erfasst und ausgewertet. Mit Beginn der Antigentestpflicht (zweimal pro Woche) für Schüler ab der Präsenzphase des Wechselunterrichts nach den Osterferien (in der KW 16/2021) wurden dem Amt die positiven Testergebnisse der Antigenlaientests der Fa. Roche [20], die den Schulen vom Land Hessen zur Verfügung gestelltworden waren, namentlich übermittelt. Diese wurden mit weiteren Meldungen, z.B. definitiv negativer PCR-Test, resp. Meldungen positiver PCR-Tests abgeglichen.

\section{Ergebnisse}

- Tab. 1 zeigt die COVID-19-Regeln und die Betriebszustände der Kitas und Schulen in FFM von der 34. KW 2020 bis zur 28. KW 2021. Sie umfasst somit das gesamte Schuljahr 2020/2021.
In - Abb. 1 ist der Verlauf der sog. 7-Tage-Inzidenzen von Beginn der Pandemie im März 2020 bis zur KW 28/2021 aufgetragen - für die Gesamtbevölkerung sowie speziell für die Kinder im Alter 5-9 Jahre und 10-14 Jahre. Die altersspezifischen Inzidenzen der Kinder stimmen insgesamt recht gut mit den Inzidenzen in der Gesamtbevölkerung überein. Einige Spitzen in den KW 19 und 25/2020 sind auf umfangreiche Reihentestungen in Unterkünften für Asylbewerber und in einer kirchlichen Gemeinde zurückzuführen, der Peak in der KW 34/2020 ist durch die Testungen der Reiserückkehrer bedingt. In der KW 16/2021, d.h. in der ersten Schulwoche nach den Osterferien, als Wechselunterricht mit Pflichttestung startete, kam es zu einem enormen Anstieg der Inzidenzen insbesondere bei den Kindern (mit Pflichttestung).

- Tab. 2 zeigt die Symptome der Kinder (0-14 Jahre), die seit Beginn der Pandemie mittels PCR-Test positiv aufSARSCoV-2 getestet wurden, aufgeschlüsselt nach unterschiedlichen Phasen der Pandemie.

Die Ergebnisse der KP-Untersuchungen in Kitas und Schulen sind in $\bullet$ Tab. 3 und Tab. 4 zusammengefasst. Die Ergebnisse im Jahr 2021 bis KW 28 sind pro Woche und in Summe aufgeführt und den summarischen Ergebnissen ab KW 34 bis KW 52/2020 [21] gegenübergestellt.

- Tab. 5 zeigt die Ergebnisse der Antigenlaientests, die nach den Osterferien ab KW 16/2021 bis zum Schuljahresende (KW 28/2021) bei Präsenz- und Wech- 
Bundesgesundheitsbl 2021 • 64:1559-1569 https://doi.org/10.1007/s00103-021-03445-3

(c) Springer-Verlag GmbH Deutschland, ein Teil von Springer Nature 2021

U. Heudorf · R. Gottschalk · A. Walczok · P. Tinnemann · K. Steul

\section{Kinder in der COVID-19 Pandemie und der Öffentliche Gesundheitsdienst (ÖGD). Daten und Überlegungen aus Frankfurt am Main}

\section{Zusammenfassung}

Hintergrund. Die Maßnahmen zur Bekämpfung der COVID-19-Pandemie haben die Entwicklungsmöglichkeiten von Kindern stark eingeschränkt. In dem Beitrag werden die Meldedaten von Kindern und die Aktivitäten des Gesundheitsamtes vor dem Hintergrund der Einschränkungen der Schulund Freizeitangebote sowie der Sport- und Vereinssportangebote diskutiert.

Material und Methode. Meldedaten aus Frankfurt am Main wurden mittels einer SURVStat-Abfrage (KW 10/2020-KW 28/2021) und aus SURVNet (bis 30.06.2021) ermittelt. Kontaktpersonen (KP) von SARS-CoV-2positiv gemeldeten Personen aus Schulen und Kitas wurden mittels PCR-Test auf SARSCoV-2 untersucht. Die Ergebnisse sowie die der seit April 2021 für Schüler verpflichtenden Antigenschnelltests werden vorgestellt. Ergebnisse. Die altersbezogenen 7-TageInzidenzen der Kinder bis 14 Jahre lagen vor der Einführung der Testpflicht für Schüler stets unter der Gesamtinzidenz, danach darüber. Die meisten Kinder mit SARS-CoV-2 hatten keine oder nur milde Symptome; eine Hospitalisierung war selten erforderlich, Todesfälle traten nicht auf. Bei den Untersuchungen der KP in Schulen und Kitas wurden meist keine und nur selten mehr als 2 positive KP gefunden. Größere Ausbrüche traten nicht auf.

Schlussfolgerung. SARS-CoV-2-Infektionen bei Kindern sind offenbar seltener und deutlich weniger schwer als bei Erwachsenen.
Größere Ausbrüche konnten im Setting Schule und Kita zuverlässig verhindert werden. Die $\mathrm{AHA}+\mathrm{L}$-Regeln und das Kontaktmanagement haben sich bewährt - auch bei hohen Inzidenzen in der lokalen Bevölkerung ohne Schnelltestpflicht und selbst bei einem hohen Anteil von besorgniserregenden Virusvarianten (Alpha und Delta) in Deutschland. Eine weitere Einschränkung des Schulund Kitabetriebs scheint deshalb weder erforderlich noch angemessen zu sein.

\section{Schlüsselwörter}

SARS-CoV-2 · Schule $\cdot$ Kindertagesstätten

\section{Children in the COVID-19 pandemic and the public health service (ÖGD). Data and reflections from Frankfurt am Main, Germany}

\section{Abstract}

Background. The measures taken to combat the COVID-19 pandemic have severely restricted the opportunities for the development of children. This paper will discuss the reporting data of children and the public health department's activities against the background of the restrictions of school and leisure time offers as well as sports and club activities.

Materials and methods. Reporting data from Frankfurt am Main, Hesse, were obtained using a SURVStat query for the calendar weeks 10/2020-28/2021 and from SURVNet (until 30 June 2021). Contact persons (CP) of SARS-CoV-2 positive persons from schools and daycare centers were screened for SARS-
CoV-2 by PCR test. These results and those of rapid antigen testing, which has been mandatory for schoolchildren since April 2021, are presented.

Results. Until Easter break, the age-related seven-day incidence values per 100,000 for children 14 years of age and younger were lower than the overall incidence; it was only higher after rapid antigen-testing was mandatory for schoolchildren. Most children with SARS-CoV-2 had no or mild symptoms; hospitalization was rarely required and no deaths occurred. Contact tracing in schools and daycare centers found no positive contacts in most cases and rarely more than two. Larger outbreaks did not occur.
Conclusion. SARS-CoV-2 infections in children appear to be less frequent and much less severe than in adults. Hygiene rules and contact management have proven themselves effective during times with high incidences in the local population without mandatory rapid antigen testing - and even with a high proportion of variants of concern (alpha and delta variants) in Germany. Against this background, further restriction of school and daycare operations appears neither necessary nor appropriate.

Keywords

SARS-CoV-2 · School · Daycare centers selunterricht durchgeführt werden mussten.

\section{Diskussion}

\section{Inzidenzwerte und deren Einflussfaktoren sowie Morbidität bei Kindern}

Die altersbezogenen Inzidenzen der Kinder lagen insbesondere in der ersten und zweiten Welle unter der Gesamt- inzidenz, ab KW 16/2021 (Schulbeginn nach den Osterferien) dann darüber (• Abb. 1). Der direkte Vergleich dieser Daten - Kinder vs. Gesamtbevölkerung bzw. verschiedene Pandemiephasen und Kalenderwochen - ist jedoch nicht möglich, da die 7-Tage-Inzidenz sehr stark von der Teststrategie und der Testverfügbarkeit beeinflusst wird. In der ersten Welle mit nur geringer Testkapazität wurden prioritär symptomatisch Infizierte mittels PCR auf SARS-CoV-2 getestet. Kinder standen nicht im Fokus der Teststrategie, sodass von einer Untererfassung ausgegangen werden muss. Im Herbst 2020 führte das Gesundheitsamt gemäß der dann gültigen Teststrategie in den Schulen und Kindergemeinschaftseinrichtungen umfangreiche Testungen der KP durch, sodass in dieser Zeit eine Untererfassung nicht wahrscheinlich ist. Parallel mit der Zunahme der Alphavariante B 1.1.7. von KW 4 bis KW 21/2021 in Deutschland (Zunahme von 6\% auf 
Tab. 1 COVID-19-Regeln und Betriebszustände in Kitas und Schulen in Frankfurt am Main (FFM), Schuljahr 2020/2021 - und jeweilige SARS-CoV-2-Inzidenzen in der Gesamtbevölkerung der Stadt

\begin{tabular}{|c|c|c|c|c|c|}
\hline $\begin{array}{l}\text { Kalender- } \\
\text { wochen }\end{array}$ & $\begin{array}{l}\text { Schule } \\
\text { Unterrichtsform }\end{array}$ & & & Kita & $\begin{array}{l}\text { Inzidenz } \\
\text { Bevölkerung FFM }\end{array}$ \\
\hline- & $\begin{array}{l}\text { Vorklassen und Klassen } \\
1-4 ; 5-6\end{array}$ & $\begin{array}{l}\text { Ab Klas- } \\
\text { se } 7\end{array}$ & $\begin{array}{l}\text { Abschluss- } \\
\text { klassen }\end{array}$ & Offen & N/7 Tage/100.000 \\
\hline- & Sommerferien & - & - & - & - \\
\hline $34-40 / 2020$ & Präsenz & Präsenz & Präsenz & $\mathrm{Ja}$ & Bis 50 \\
\hline $41-42 / 2020$ & Herbstferien & Ferien & Ferien & $\mathrm{Ja}$ & $70-130$ \\
\hline $43-51 / 2020$ & Präsenz & Präsenz & Präsenz & Ja & $191-316$ \\
\hline $52-1 / 2021$ & Weihnachtsferien & Ferien & Ferien & Ja & $191-144$ \\
\hline $2-7 / 2021$ & Distanz & Distanz & Präsenz & Ja & $124-59$ \\
\hline $8-13 / 2021$ & Wechsel & Distanz & Präsenz & Ja & $81-170$ \\
\hline $14-15 / 2021$ & Osterferien & Ferien & Ferien & Ja & $139-173$ \\
\hline $16 / 2021^{\mathrm{a}}$ & Wechsel & Distanz & Präsenz & Ja & 217 \\
\hline $17-18 / 2021^{a}$ & Distanz & Distanz & $\begin{array}{l}\text { Präsenz/ } \\
\text { Wechsel }\end{array}$ & $\mathrm{Ja}$ & $200-147$ \\
\hline $19-20 / 2021^{a}$ & Wechsel & Wechsel & Wechsel & $\mathrm{Ja}$ & $118-80$ \\
\hline $21 / 2021^{\mathrm{a}}$ & Präsenz & Wechsel & Präsenz & Ja & 54 \\
\hline $22-28 / 2021^{a}$ & Präsenz & Präsenz & Präsenz & Ja & $19-35$ \\
\hline- & Sommerferien & - & - & - & - \\
\hline
\end{tabular}

Tab. 2 Symptome bei Kindern und Jugendlichen (0-14 J.) in Frankfurt am Main mit positivem PCR-Nachweis auf SARS-CoV-2: getrennt nach erster, zweiter und dritter Welle

\begin{tabular}{|c|c|c|c|c|c|c|}
\hline \multirow[t]{2}{*}{-} & \multicolumn{2}{|c|}{$\begin{array}{l}\text { Erste Welle }^{a} \\
\text { März-August } 2020\end{array}$} & \multicolumn{2}{|c|}{$\begin{array}{l}\text { Zweite Welle } \\
\text { Okt. 2020-Febr. } 2021\end{array}$} & \multicolumn{2}{|c|}{$\begin{array}{l}\text { Dritte Welle } \\
\text { März-Juni } 2021\end{array}$} \\
\hline & $n$ & $\%$ & $n$ & $\%$ & $n$ & $\%$ \\
\hline Alle Kinder & 219 & - & 1626 & - & 1878 & - \\
\hline \multicolumn{7}{|c|}{ Verschiedene Symptome } \\
\hline Fieber & 41 & 18,7 & 340 & 20,9 & 388 & 20,7 \\
\hline Husten & 16 & 7,3 & 273 & 16,8 & 406 & 21,6 \\
\hline Halsschmerzen & 12 & 5,5 & 162 & 10,0 & 229 & 12,2 \\
\hline Schnupfen & 18 & 8,2 & 277 & 17,0 & 384 & 20,4 \\
\hline Geruchsstörung & 12 & 5,5 & 88 & 5,4 & 50 & 2,7 \\
\hline Geschmacksstörung & 11 & 5,0 & 104 & 6,4 & 41 & 2,2 \\
\hline Durchfall & 6 & 2,7 & 45 & 2,8 & 56 & 3,0 \\
\hline Keine Symptome & 142 & 64,8 & 840 & 51,7 & 817 & 43,5 \\
\hline \multicolumn{7}{|c|}{ Schwere Atemwegssymptome } \\
\hline Dyspnoe & 0 & 0 & 10 & 0,6 & 7 & 0,4 \\
\hline ARDS & 0 & 0 & 2 & 0,1 & 5 & 0,3 \\
\hline Pneumonie & 0 & 0 & 1 & 0,1 & 0 & 0,0 \\
\hline Beatmung & 0 & 0 & 1 & 0,1 & 0 & 0,0 \\
\hline \multicolumn{7}{|c|}{ Hospitalisierung oder Tod } \\
\hline Hospitalisierung & 8 & 3,7 & 42 & 2,6 & 31 & 1,7 \\
\hline Tod & 0 & 0 & 0 & 0,0 & 0 & 0,0 \\
\hline
\end{tabular}

$94 \%)$ nahmen die Inzidenz in der Gesamtbevölkerung und die altersbezogene Inzidenz der Kinder in FFM zu. Der Peak bei den 5 - bis 14-jährigen Kindern in KW 16/2021 ist demgegenüber sicherlich durch die Testpflicht mittels Antigentest (mit)bedingt. Durch die Testpflicht wurde - allerdings mit den Grenzen der Methode, s. unten - erstmals die „Dunkelziffer“ bei den Schülern der Vorklassen und der Klassen 1-6 in FFM untersucht (insgesamt ca. 39.000 Schüler). $\mathrm{Da}$ in keiner anderen Altersgruppe eine solche Testpflicht bestand, können die so erhaltenen Daten der Kinder nicht mit den Gesamtdaten verglichen werden [22]. Ähnliche Ergebnisse wurden auch aus Bayern nach den Osterferien 2021 beschrieben: Dort nahm in Kreisen mit Wechselunterricht und verpflichtenden Antigentestungen die Zahl der in der ersten Schulwoche nach den Ferien positiv auf SARS-CoV-2 getesteten Kinder und Jugendlichen (5-20 Jahre) auf das 2- bis 4-Fache $\mathrm{zu}$, während in Kreisen, in denen aufgrund höherer 7-TageInzidenzen Distanzunterricht stattfand (ohne Pflichttestung) die Inzidenzen nicht anstiegen [23].

Bis zum Schuljahresende in KW 28/ 2021 nahmen die Inzidenzen bei den Kindern kontinuierlich ab (•Abb. 1), trotz Präsenzunterricht mit Testpflicht und trotz der zunehmenden Verbreitung der Deltavariante in Deutschland (belastbare Daten für FFM liegen hier nicht vor) von $1 \%$ in $\mathrm{KW} 17 / 2021$ auf $93 \%$ in KW 28/2021, sie blieben aber angesichts der weiterbestehenden zweimal wöchentlichen Antigentestpflicht leicht über der Gesamtinzidenz.

Letztendlich beeinflusst die Teststrategie auch die angegebenen Symptome der positiv auf SARS-CoV-2 Getesteten (- Tab. 2). In der ersten Welle waren 2 Drittel der - oft im Rahmen von Ausbruchsuntersuchungen z. B. in sozialen Einrichtungen (Kirchengemeinde, Flüchtlingsunterkünfte) - positiv getesteten Kinder asymptomatisch, ab Herbst 2020 waren es noch etwa die Hälfte. Ab Herbst 2020 wurden bei Kindern häufig die „Erkältungssymptome“ wie Husten, Schnupfen und Halsschmerzen berichtet, während die für COVID-19 sehr typischen Symptome wie Geruchs- und 
Geschmacksstörungen nur bei ca. 3\% der Kinder (im Vergleich Erwachsene ca. $20 \%$ ) angegeben wurden. Schwere Atemwegssymptome bei Kindern wurden nur in Einzelfällen angegeben. Auch Hospitalisierungen waren bei Kindern deutlich seltener als bei Erwachsenen. Damit bestätigen unsere Daten die Berichte aus vielen Publikationen, wonach SARS-CoV-2-Infektionen bei Kindern und Jugendlichen weniger schwer verlaufen als bei Erwachsenen [24-30].

\section{Hygienemaßnahmen}

Im Zusammenhang mit der schrittweisen Wiederöffnung der Schulen ab Mai 2020 führten Mitarbeiter des Gesundheitsamtes Hygienebegehungen in allen Schulen durch: Diese zeigten - im Gegensatz zu früheren Erhebungen [31, 32] eine gute Hygiene und eine sehr gute Umsetzung der COVID-19-Hygieneregeln [33]. Die Schulen resp. die Schulämter hatten eine angemessene Ausstattung der Sanitäreinheiten einschließlich der Waschbereiche sichergestellt und die Reinigung durch Präsenzkräfte und/oder Erhöhung der Reinigungsfrequenz verbessert. Die organisatorischen Vorgaben des Kultusministeriums wie Abstandsregeln und Wegeführung wurden befolgt, wobei das Tragen von Masken auf Wegen (Weg zum Sitzplatz, Flure, Sanitäreinrichtungen) weitgehend umgesetzt war. Zu diesem Zeitpunkt war das Tragen einer Maske am Sitzplatz in der Klasse noch nicht grundsätzlich empfohlen; erst nach der Stellungnahme der pädiatrischen Fachgesellschaften [34] und bei „Präsenzunterricht unter COVID-19-Bedingungen“ sowie den hohen Inzidenzen im Herbst wurde die Empfehlung des grundsätzlichen Maskentragens auch im Unterricht umgesetzt. In mehr als einem Viertel der Schulen waren zumindest in einigen Räumen raumlufttechnische Anlagen vorhanden, wobei der Schulgemeinde der aktuelle Betriebszustand der Anlagen, die aus Energiespargründen meist nur im Winter betrieben werden, oftmals nicht bekannt war. Dies steht in Übereinstimmung mit der jahrelangen Erfahrung des Gesundheitsamtes. Unter Umständen kann so evtl. zu wenig gelüftet worden sein, wie dies in den Vorjahren auch immer wieder festgestellt werden musste $[35,36]$.

Ab Sommer 2020 wurden die AHARegeln um das sachgerechte Lüften (AHA + L-Regel) ergänzt. Deswegen wiederholte die Stadt FFM im Herbst 2020 ihre Lüftungskampagne „Frische Luft für frisches Denken“ in den Schulen und Kitas und warb mit einem im Hinblick auf COVID-19 aktualisierten Lüftungsflyer für die sachgerechte Lüftung in Schulen [33, 37]. Die Anschaffung von sog. Luftreinigungsgeräten, die teilweise von Eltern und Lehrern dringend gefordert wurde, lehnte das Gesundheitsamt - in Übereinstimmung mit Stellungnahmen der Deutschen Gesellschaft für Krankenhaushygiene (DGKH) und des Umweltbundesamtes (UBA) - ab [38, 39]. Es bleibt zu hoffen, dass die im Rahmen der COVID-19-Pandemie erreichten Verbesserungen, insbesondere in der Sanitär- und Raumlufthygiene, nachhaltig sein werden. Die Gesundheitsämter sollten dies überprüfen [40].

\section{Kontaktpersonenmanagement}

Ab Beginn des Schuljahres 2020/2021 haben Mitarbeiter des Gesundheitsamtes nach Feststellung einer „Indexperson“ (Kind oder Erwachsener) sowohl in Kitas als auch in Schulen die KP mit „ungeschützten Kontakten“ (d.h. für 15 min weniger als $2 \mathrm{~m}$ Abstand zu Kontaktpersonen ohne Maske) erfasst. Allen KP wurden auf freiwilliger Basis und unabhängig vom Vorhandensein von Symptomen die Entnahme von Nasen-Rachen-Abstrichen sowie die kostenlose PCR-Testung auf SARS-CoV-2 nahegelegt. Die Mehrzahl der KP (ca. 85\%) nahm das Angebot an. Die Abstriche fanden erst 5-7 Tage nach dem ermittelten letzten Kontakt mit dem „Indexfall“ statt, um etwaige falsch-negative Testergebnisse in der Inkubationszeit zu vermeiden. Insgesamt wurden nur wenige Kontaktpersonen positiv auf SARS-CoV-2 getestet (- Tab. 3 und 4). Die Positivenrate blieb selbst zu Zeiten des Präsenzunterrichts bei „Normalbetrieb unter COVID-19“ und hoher Gesamtinzidenzen im Herbst 2020 bei wenigen Prozent und deutlich unter der zur gleichen Zeit publizierten allgemeinen Positivenrate der Labo- re insgesamt [21]. Auch in den Wochen der Ausbreitung der Alphavariante (2021: KW 4: $6 \%$; KW 21:94\%) und der Deltavariante (2021: KW 17: 1\%; KW 28: $93 \%$ ) in Deutschland blieb die Positivenrate bei den KP-Testungen gering bzw. nahm weiter ab. Bei $68 \%$ der Indexfälle in Kitas und bei $78 \%$ in Schulen wurden keine KP positiv getestet, in $24 \%$ (Schulen: $18 \%$ ) der Fälle 1-2 KP und in $8 \%$ (Schulen: $4 \%$ ) mehr als $2 \mathrm{KP}$, mit einem Maximalwert von 5 Personen. 2021 waren in Kitas in $54 \%$ der Vorgänge Erwachsene die Indexpersonen, in den Schulen in $18 \%$. Bei Erwachsenen als Indexpersonen wurden in Kitas 2,5-mal und in Schulen 1,8-mal mehr KP positiv getestet, im Vergleich $\mathrm{zu}$ Kindern als Indexpersonen. Die hohen KP-Testzahlen ab der KW 24/2021 (- Tab.4) sind durch eine Schule zu erklären, in welcher nach Indexfällen bei unklarer Datenlage nicht nur eventuelle Kontaktpersonen, sondern alle an der Schule Betreuten und Tätigen - teilweise mehrfach - mittels PCR-Test aus dem Rachenabstrich untersucht wurden. Größere Ausbrüche, wie sie vereinzelt aus Schulen berichtet wurden [41, 42], wurden in FFM nicht bekannt.

Die Zahl der Isolierungen von positiv auf SARS-CoV-2 Getesteten und der quarantänisierten KP in Schulen konnte durch die Maßnahmen niedrig gehalten werden. Dies wurde auch aus anderen Regionen so berichtet [43, 44]. Ausbruchsuntersuchungen zeigten, dass Schulen und Kitas vergleichsweise selten betroffen waren und die Fälle auf wenige Personen beschränkt blieben [45-48].

Die Ergebnisse aus den umfangreichen Kontaktpersonenuntersuchungen in den Frankfurter Schulen stimmen gut mit den Daten aus anderen Regionen und Ländern überein. Nicht nur in Zeiten noch niedriger Gesamtinzidenzen, sondern auch bei hohen Inzidenzen und allgemeinem Präsenzbetrieb wurden nur wenige $\mathrm{KP}$ in Schulen oder Kitas positiv auf SARS-CoV-2 getestet [49-62]. Besonders erwähnenswert ist dabei eine landesweite Erhebung aus RheinlandPfalz bis Ende Dezember 2020, die zeigte, dass es bei 784 Indexfällen nur in jedem 6. Fall zu Übertragungen kam: Waren Lehrer die Indexperson, kam es dreimal häufiger $\mathrm{zu}$ Transmissionen 


\section{Leitthema}

Tab. 3 Untersuchung von Kontaktpersonen in Kitas in Frankfurt am Main. Vorgänge und Testungen in den Kalenderwochen (KW) 1-28/2021 - im

Vergleich mit KW 35-52/2020

\begin{tabular}{|c|c|c|c|c|c|c|c|c|}
\hline Kalenderwoche & $\begin{array}{l}\text { 7-Tage-Inzidenz Bevöl- } \\
\text { kerung Frankfurt a. M. }\end{array}$ & $\begin{array}{l}\text { Vorgänge } \\
\text { (n) }\end{array}$ & $\begin{array}{l}\text { Erwachsene } \\
\text { getestet }(n)\end{array}$ & $\begin{array}{l}\text { Erwachsene } \\
\text { positiv (n) }\end{array}$ & $\begin{array}{l}\text { Erwachsene } \\
\text { positiv (\%) }\end{array}$ & $\begin{array}{l}\text { Kinder } \\
\text { getestet }(n)\end{array}$ & $\begin{array}{l}\text { Kinder } \\
\text { positiv (n) }\end{array}$ & $\begin{array}{l}\text { Kinder } \\
\text { positiv (\%) }\end{array}$ \\
\hline 1 (Ferien) & 144 & 1 & 19 & 0 & 0 & 63 & 2 & 3,2 \\
\hline 2 & 124 & 3 & 23 & 1 & 4,3 & 20 & 2 & 10,0 \\
\hline 3 & 86 & 8 & 32 & 2 & 6,3 & 58 & 2 & 3,4 \\
\hline 4 & 76 & 9 & 51 & 2 & 3,9 & 101 & 4 & 4,0 \\
\hline 5 & 75 & 8 & 55 & 1 & 1,8 & 111 & 2 & 1,8 \\
\hline 6 & 60 & 9 & 65 & 2 & 3,1 & 215 & 11 & 5,1 \\
\hline 7 & 59 & 9 & 90 & 1 & 1,1 & 128 & 3 & 2,3 \\
\hline 8 & 81 & 3 & 21 & 0 & 0 & 42 & 0 & 0 \\
\hline 9 & 81 & 9 & 41 & 0 & 0 & 130 & 2 & 1,5 \\
\hline 10 & 109 & 19 & 143 & 5 & 3,5 & 302 & 22 & 7,3 \\
\hline 11 & 134 & 17 & 171 & 8 & 4,7 & 295 & 14 & 4,7 \\
\hline 12 & 151 & 24 & 151 & 5 & 3,3 & 405 & 30 & 7,4 \\
\hline 13 & 170 & 19 & 97 & 4 & 4,1 & 310 & 47 & 15,2 \\
\hline 14 (Ferien) & 139 & 9 & 48 & 0 & 0 & 128 & 1 & 0,8 \\
\hline 15 (Ferien) & 173 & 13 & 73 & 3 & 4,1 & 171 & 7 & 4,1 \\
\hline 16 & 217 & 25 & 137 & 1 & 0,7 & 401 & 8 & 2,0 \\
\hline 17 & 201 & 25 & 112 & 1 & 0,9 & 277 & 3 & 1,1 \\
\hline 18 & 147 & 17 & 68 & 3 & 4,4 & 226 & 10 & 4,4 \\
\hline 19 & 118 & 7 & 24 & 0 & 0 & 52 & 1 & 1,9 \\
\hline 20 & 80 & 5 & 24 & 0 & 0 & 65 & 1 & 1,5 \\
\hline 21 & 54 & 9 & 22 & 0 & 0 & 124 & 5 & 4,0 \\
\hline 22 & 35 & 4 & 19 & 0 & 0 & 63 & 1 & 1,6 \\
\hline 23 & 27 & 6 & 36 & 0 & 0 & 125 & 2 & 1,6 \\
\hline 24 & 20 & 6 & 40 & 0 & 0 & 120 & 0 & 0 \\
\hline 25 & 19 & 3 & 13 & 0 & 0 & 139 & 0 & 0 \\
\hline 26 & 21 & 2 & 15 & 0 & 0 & 35 & 1 & 2,8 \\
\hline 27 & 24 & 5 & 39 & 0 & 0 & 143 & 1 & 0,7 \\
\hline 28 & 31 & 4 & 24 & 0 & 0 & 70 & 1 & 1,4 \\
\hline $\begin{array}{l}\text { Summe } \\
\text { KW 1-28/2021 }\end{array}$ & $21-217$ & 278 & 1653 & 39 & 2,4 & 4319 & 183 & 4,2 \\
\hline $\begin{array}{l}\text { Vergleich } \\
\text { KW 35-52/2020 } \\
{[21]}\end{array}$ & $22-317$ & 164 & 1062 & 48 & 4,5 & 3065 & 78 & 2,5 \\
\hline
\end{tabular}

verglichen $\mathrm{zu}$ Kindern als Indexpersonen. Lehrer verursachten viermal mehr Sekundärfälle als Kinder - und dies häufig bedingt durch Kontakte zwischen Lehrern [62]. Auch in England waren in mehr als der Hälfte der Ausbrüche in Schulen ausschließlich Mitarbeiter und keine Schüler betroffen [63]. Darüber hinaus zeigte sich sowohl in England als auch in Finnland, dass die Wiederöffnung der Schulen/Kindereinrichtungen nicht automatisch zu einer Zunahme der Inzidenz geführt hat [64-66].

\section{Testverfahren und ihre Grenzen}

Ein positiver Test bei einer Kontaktperson bedeutet nicht automatisch, dass die Übertragung im Schulsetting geschah, oftmals ergab sich bei genaueren Recherchen, dass die Übertragungen im Privatoder Freizeitbereich stattgefunden haben mussten [21]. Besonders deutlich wurde dies nach den Osterferien 2021, als im Zusammenhang mit der Antigentestpflicht für die Schüler in der Präsenzphase des Wechselunterrichts die höchsten Inzidenzen bei 5- bis 14-Jährigen gefunden wurden (• Abb. 1). Da die Testung unmittelbar nach 14 Tagen Ferien und zu Beginn des Unterrichts vorgenommen wurde, müssen die Infektionen in den Ferien erworben worden sein [22]. Die Autorengruppe aus Bayern (s. oben), die ebenfalls die Situation der Schulkinder nach den Osterferien in Bayern untersucht hatte, betrachtete die Datenlage dieser Kalenderwoche als „natürliches Experiment", da alle Schulkinder in den 2 vorhergehenden Ferienwochen nicht in die Schule gegangen waren und die Neuinfektionen somit mit sehr hoher Wahrscheinlichkeit außerhalb der Schule stattgefunden haben müssen [23].

Die von Fachleuten anzuwendenden Antigenschnelltests auf SARS-CoV-2 
Tab. 4 Untersuchung von Kontaktpersonen in Schulen in Frankfurt am Main. Vorgänge und Testungen in den Kalenderwochen (KW) 1-28/2021 - im Vergleich mit KW 35-52/2020

\begin{tabular}{|c|c|c|c|c|c|c|c|c|}
\hline Kalenderwoche & $\begin{array}{l}\text { 7-Tage-Inzidenz Bevöl- } \\
\text { kerung Frankfurt a. M. }\end{array}$ & $\begin{array}{l}\text { Vorgänge } \\
\text { (n) }\end{array}$ & $\begin{array}{l}\text { Erwachsene } \\
\text { getestet }(n)\end{array}$ & $\begin{array}{l}\text { Erwachsene } \\
\text { positiv (n) }\end{array}$ & $\begin{array}{l}\text { Erwachsene } \\
\text { positiv (\%) }\end{array}$ & $\begin{array}{l}\text { Kinder } \\
\text { getestet }(n)\end{array}$ & $\begin{array}{l}\text { Kinder } \\
\text { positiv (n) }\end{array}$ & $\begin{array}{l}\text { Kinder } \\
\text { positiv (\%) }\end{array}$ \\
\hline 1 (Ferien) & 144 & - & - & - & - & 7 & 0 & 0 \\
\hline 2 & 124 & - & - & - & - & 0 & 0 & 0 \\
\hline 3 & 86 & - & - & - & - & 0 & 0 & 0 \\
\hline 4 & 76 & - & - & - & - & 0 & 0 & 0 \\
\hline 5 & 75 & 1 & 5 & 0 & 0 & 0 & 0 & 0 \\
\hline 6 & 60 & 4 & 17 & 0 & 0 & 43 & 2 & 4,7 \\
\hline 7 & 59 & - & - & - & - & 20 & 0 & 0 \\
\hline 8 & 81 & - & - & - & - & 0 & 0 & 0 \\
\hline 9 & 81 & 3 & 52 & 0 & 0 & 1 & 0 & 0 \\
\hline 10 & 109 & 2 & 14 & 0 & 0 & 74 & 0 & 0 \\
\hline 11 & 134 & 4 & 18 & 0 & 0 & 60 & 1 & 1,7 \\
\hline 12 & 151 & 9 & 90 & 1 & 1,1 & 226 & 7 & 3,1 \\
\hline 13 & 170 & 1 & 1 & 0 & 0 & 20 & 0 & 0 \\
\hline 14 (Ferien) & 139 & 0 & 0 & 0 & 0 & 0 & 0 & 0 \\
\hline 15 (Ferien) & 173 & 0 & 0 & 0 & 0 & 0 & 0 & 0 \\
\hline 16 & 217 & 0 & 0 & 0 & 0 & 0 & 0 & 0 \\
\hline 17 & 201 & 0 & 0 & 0 & 0 & 0 & 0 & 0 \\
\hline 18 & 147 & 1 & 1 & 0 & 0 & 9 & 0 & 0 \\
\hline 19 & 118 & 0 & 0 & 0 & 0 & 0 & 0 & 0 \\
\hline 20 & 80 & 0 & 0 & 0 & 0 & 0 & 0 & 0 \\
\hline 21 & 54 & 0 & 0 & 0 & 0 & 0 & 0 & 0 \\
\hline 22 & 35 & 1 & 22 & 0 & 0 & 9 & 0 & 0 \\
\hline 23 & 27 & 0 & 0 & 0 & 0 & 0 & 0 & 0 \\
\hline 24 & 20 & 2 & 23 & 0 & 0 & 158 & 5 & 3,2 \\
\hline 25 & 19 & 3 & 37 & 0 & 0 & 301 & 1 & 0,3 \\
\hline 26 & 21 & 5 & 107 & 0 & 0 & 371 & 1 & 0,3 \\
\hline 27 & 24 & 3 & 19 & 0 & 0 & 61 & 0 & 0 \\
\hline 28 & 31 & 6 & 34 & 1 & 2,9 & 349 & 1 & 0,3 \\
\hline $\begin{array}{l}\text { Summe } \\
\text { KW 1-28/2021 }\end{array}$ & $21-217$ & 45 & 440 & 2 & 0,45 & 1709 & 18 & 1,05 \\
\hline $\begin{array}{l}\text { Vergleich } \\
\text { KW 35-52/2020 } \\
{[21]}\end{array}$ & $22-317$ & 110 & 897 & 8 & 0,9 & 2891 & 71 & 2,5 \\
\hline
\end{tabular}

haben eine deutlich geringere Sensitivität als PCR-Tests [67]. Zu den Tests für Laien liegen noch weniger aussagekräftige Daten vor. Der in Hessen bei den Schülern eingesetzte Laientest des Herstellers Roche verfügt nach Angaben der Hersteller über eine Sensitivität von $82 \%$ und eine Spezifität von $100 \%$ [20], eine herstellerunabhängige Validierung unter Realbedingungen liegt bislang nicht vor. $\mathrm{Da}$ negative Antigentests nicht mittels PCR nachuntersucht wurden, kann auch aus unseren Daten die Sensitivität des Antigentests nicht abgeschätzt werden. Unter Realbedingungen, d.h. zweimal wöchentliche Tests von 39.000 Schü- lern, wurden nur $61,3 \%$ der positiven Antigentests nachweislich durch einen positiven PCR-Test bestätigt ( $\bullet$ Tab. 5). Bei einer groben Schätzung einer zweimal in der Woche erfolgten Testung von ca. 39.000 Kindern über 11 Wochen (kein Präsenzunterricht in KW 17 und 18/2021) wurden in dieser Zeit in FFM ca. 850.000 Antigenschnelltests vorgenommen, $796(0,1 \%)$ waren positiv, wovon $488(0,06 \%)$ dokumentiert mittels PCR bestätigt wurden.

Eine weitere Studie zu Antigentests im „realen Leben“ wurde im Herbst 2020 in Hessen durchgeführt. 635 Lehrer aus 86 Schulen testeten sich - nach intensiver Einweisung - alle $48 \mathrm{~h}$ mittels Antigentests RAT (RIDA ${ }^{\circledR}$ QUICK SARS-CoV-2 Antigen Test, R-Biopharm, Darmstadt, Germany) auf SARS-CoV-2. Positive Schnelltests wurden im Labor mittels PCR nachuntersucht. Insgesamt 21 (0,19\%) der 11.385 Antigentests fielen positiv aus, 16 davon wurden als falsch-positiv detektiert, d.h., die Rate der durch PCR-Test bestätigten Fälle betrug $0,04 \%$ [68].

In Österreich wurde im Februar 2021 ebenfalls eine Antigentestpflicht für 1.016.234 Kinder im Präsenzunterricht eingeführt. Österreichweit waren in der 8. KW 619 (0,05\%) der präsenten Schüler 
Tab. 5 Ergebnisse der Pflichtantigentestungen, die den Präsenz-und Wechselunterricht in Schulen in Kalenderwoche (KW) 16-28/2021 begleiteten, einschließlich der dokumentierten Kontrollen mittels PCR-Test; Daten aus Frankfurt am Main

\begin{tabular}{|c|c|c|c|c|c|}
\hline $\begin{array}{l}\text { Kalender- } \\
\text { woche }\end{array}$ & $\begin{array}{l}\text { Antigentests } \\
\text { positiv (n) }\end{array}$ & $\begin{array}{l}\text { PCR-Test } \\
\text { positiv }(n)^{a}\end{array}$ & $\begin{array}{l}\text { PCR-Test } \\
\text { positiv (\%) }\end{array}$ & $\begin{array}{l}\text { PCR-Test } \\
\text { negativ }(n)^{a}\end{array}$ & $\begin{array}{l}\text { PCR-Test } \\
\text { negativ (\%) }\end{array}$ \\
\hline 16 & 199 & 147 & 73,9 & 13 & 6,5 \\
\hline 17 & 70 & 54 & 77,1 & 5 & 7,1 \\
\hline 18 & 67 & 48 & 71,6 & 10 & 14,9 \\
\hline 19 & 61 & 36 & 59,0 & 9 & 14,8 \\
\hline 20 & 98 & 63 & 64,3 & 15 & 15,3 \\
\hline 21 & 66 & 40 & 60,6 & 10 & 15,2 \\
\hline 22 & 40 & 20 & 50,0 & 10 & 25,0 \\
\hline 23 & 53 & 28 & 52,8 & 6 & 11,3 \\
\hline 24 & 36 & 16 & 44,4 & 10 & 27,8 \\
\hline 25 & 31 & 15 & 48,4 & 7 & 22,6 \\
\hline 26 & 31 & 14 & 45,2 & 9 & 29,0 \\
\hline 27 & 19 & 5 & 26,3 & 4 & 21,1 \\
\hline 28 & 25 & 2 & 8,0 & 9 & 36,0 \\
\hline KW 16-28 & 796 & 488 & 61,3 & 117 & 14,7 \\
\hline
\end{tabular}

${ }^{a}$ Dargestellt sind die dem Gesundheitsamt gemeldeten Tests; es kann nicht sicher angegeben werden, dass jeder positive Antigentest überprüft worden ist

im Antigentest positiv. An den weitaus meisten Schulen wurde kein Kind, selten einzelne Kinder positiv getestet. Nur in $33(0,7 \%)$ der 5000 Schulstandorte wurde mehr als 1 Fall pro Klasse positiv auf SARS-CoV-2 getestet [69].

Vor diesem Hintergrund wurde die Antigentestpflicht in der Risiko-, Aufwand- und Nutzenbewertung als nicht geeignet und nicht verhältnismäßig eingestuft [70, 71]. Frühzeitig wurde auf die möglichen negativen psychologischen Auswirkungen repetitiver Testungen hingewiesen [72]. Berichte, wonach Schulkinder beispielsweise „nach einem kollektiven Schnelltest bei positivem Ausgang hektisch und als ginge es in Polizeigewahrsam ,abgeführt" werden“" [73], zeigen, dass diese Hinweise ernst zu nehmen sind.

Zusammengefasst deuten die Ergebnisse darauf hin, dass Schulen und auch sonstige Kindertageseinrichtungen keine Risikobereiche sind und Infektionseinträge durch gute Hygiene und Kontaktpersonenmanagement gut beherrschbar sind. Darüber hinaus erwerben Kinder SARS-CoV-2 häufig (häufiger?) im Privatbereich, wo sie darüber hinaus seltener als Erwachsene andere infizieren [74] . Kinder nehmen am Infektionsgeschehen teil, ohne aber selbst „Treiber der Pan-

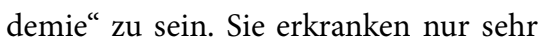

selten schwer an COVID-19 und sind seltener als Erwachsene Überträger.

Die negativen Folgen der Schulschließungen und des Lockdowns, vor denen seit Beginn der Pandemie gewarnt wurde, werden zunehmend deutlich [3-10, 75, 76]. In einer bereits im Mai/Juni 2020 durchgeführten repräsentativen Untersuchung gaben 7- bis 17-jährige Kinder und Jugendliche im Vergleich mit der repräsentativen Bella-Studie (2014-2017) eine signifikant niedrigere gesundheitliche Lebensqualität (40,2\% vs. $15,3 \%)$ und mehr gesundheitliche Probleme (17,8\% vs. 9,9\%) sowie höhere Angstlevel (24,1\% vs. 14,9\%) an [75]. Es kann angenommen werden, dass sich die Situation mit zunehmender Dauer der einschränkenden Maßnahmen verschärft, ebenso bei den Kinderschutzfällen [10]. Bei der Befragung von 1560 Schülern (Median 15 Jahre) aus Dresden mit verschiedenen standardisierten Befragungsinstrumenten (u.a. auch einen Long-COVID-Survey-Fragebogen) gab ein Drittel der Kinder und Jugendlichen an, in den letzten 7 Tagen an den erfragten Symptomen (Konzentrationsschwäche, Gedächtnisverlust, Unruhe, Kopf-, Bauch-, Muskel- und Gliederschmerzen, Fatigue, Schlafstörungen) gelitten zu haben - ohne statistisch signifikante Unterschiede zwischen den 188 sero- positiven und den 1365 seronegativen Schülern [76].

Vor diesem Hintergrund erscheint eine weitere Einschränkung des Präsenzunterrichts weder legitim noch geeignet, erforderlich oder angemessen, um Infektionen bei Kindern oder deren Kontaktpersonen zu verhüten. Da die Schulen keinen Risikobereich darstellen, sollte auch auf die erheblichen Aufwendungen (Finanzen, Umweltbelastung) für verpflichtende Schnelltests verzichtet werden. Aus psychologischer Sicht suggerieren die Schnelltests eine Gefahr, die nicht vorhanden ist. Die Gelder könnten an anderer Stelle in Schulen viel besser eingesetzt werden [22]. Es stellt sich die Frage, warum diese und andere Forderungen aus dem Öffentlichen Gesundheitsdienst (ÖGD; $[21,22,60,77-80])$ in der Politik und den Medien kein Gehör finden ebenso wenig wie die zahlreichen seit einem Jahr von pädiatrischen Fachverbänden und der Deutschen Gesellschaft für Krankenhaushygiene publizierten Stellungnahmen [3-9].

Die Politik hat die großen Leistungen des ÖGD in der Pandemiebekämpfung wahrgenommen und im September 2020 den Pakt für den öffentlichen Gesundheitsdienst beschlossen [81]. Obwohl in diesem Pakt explizit auf das Leitbild des ÖGD hingewiesen wird (Gesundheitsschutz, Beratung und Information, Gesundheitsförderung und Prävention, Gesundheitsberichterstattung, Gesundheitsplanung, Öffentlichkeitsarbeit und Politikberatung [16]), werden die Kompetenzen des ÖGD in den anderen wichtigen Präventionsbereichen nicht genutzt, sondern lediglich auf die unmittelbare Pandemiebearbeitung (Meldewesen, Isolierung, Quarantänisierung) begrenzt. In vielen Gesundheitsämtern müssen weiterhin fast alle Kräfte im Infektionsmanagement eingesetzt und selbst gesetzliche Pflichtaufgaben weiterer Bereiche, einschließlich der Präventionsaufgaben des KJGD, weitgehend reduziert oder sogar ausgesetzt werden. Nachdem Schuleingangsuntersuchungen für ein Jahr ausgesetzt waren, wurden sie in FFM nach den Osterferien 2021 wieder angeboten, allerdings nur für Kinder mit besonderen Bedar- 
fen. Auch die sozialpädiatrische Arbeit des KJGD - Beratung, sozialpädiatrische Gutachten bis hin zu den „Frühen Hilfen" - wurde nur noch in reduzierter Form angeboten. Eine Umfrage aus Nordrhein-Westfalen zeigte, dass die Situation in anderen Gesundheitsamtsbereichen vergleichbar war/ist: In den befragten Ämtern wurden Schuleingangsuntersuchungen, zielgruppen- und bedarfsorientierte Untersuchungen, sozialpädiatrische Gutachten, Kooperation mit Kinderschutz und Frühen Hilfen nur noch reduziert wahrgenommen und Impfprojekte, Gesundheitsberichterstattung gar vollständig ausgesetzt. Die Autorinnen sehen das im Hinblick auf die Entwicklungschancen von Kindern und den Präventionsauftrag der Gesundheitsämter für die Kinder kritisch [13]. Erste orientierende Berichte aus den wiederaufgenommenen Schuleingangsuntersuchungen in FFM bestätigen die vielfach geäußerten Befürchtungen: Durch die erzwungene Bewegungsarmut (kein Vereinssport, teilweise geschlossene Spielplätze) haben viele Kinder Übergewicht entwickelt und die sprachliche Entwicklung ist insbesondere bei Kindern mit Migrationshintergrund oder aus sozial schwierigeren Verhältnissen erheblich verzögert. Auch Kinderschutzfälle wurden vermehrt festgestellt.

Von den verschiedenen Maßnahmen, die zur Bekämpfung der COVID-19-Pandemie von der politischen Ebene beschlossen wurden, haben letztlich nur die $\mathrm{AHA}+\mathrm{L}-$ Vorgaben eine sichere Evidenz. Die jeweiligen Level der 7-Tage-Inzidenzen wurden nicht durch Erfahrungen des ÖGD festgelegt, sondern willkürlich als Grenzen für einzuleitende Maßnahmen gesetzt.

Viele der Probleme, die durch die massiven Einschränkungen der Grundrechte der Menschen in Deutschland entstanden sind, wären bei nüchterner evidenzbasierter Einschätzung durch den ÖGD vermeidbar gewesen. Leider war dieser aber bei den Beratungen der Politik nur selten beteiligt.

\section{Korrespondenzadresse}

\section{Katrin Steul}

Gesundheitsamt Frankfurt am Main

Breite Gasse 28, 60313 Frankfurt, Deutschland

katrin.steul@stadt-frankfurt.de

Danksagung. Die Autoren danken dem „Team Schule und Kita" des Gesundheitsamtes, das durch seine umsichtige Arbeit diesen Artikel ermöglicht hat (Bauer J, Becht C, Ciftci P, Engel H, Latta A, Mayer S, Müller B, Polat H, Sauer A, Scheuer C, Wihstutz W).

\section{Einhaltung ethischer Richtlinien}

Interessenkonflikt. U. Heudorf, R. Gottschalk, A. Walczok, P. Tinnemann und K. Steul geben an, dass kein Interessenkonflikt besteht.

Für diesen Beitrag wurden von den Autoren keine Studien an Menschen oder Tieren durchgeführt.

\section{Literatur}

1. Hessen (2021) Verordnungen und Allgemeinverfügungen. https://www.hessen.de/fuerbuerger/corona-hessen/verordnungen-undallgemeinverfuegungen. Zugegriffen: 4. Aug. 2021

2. Bundesamt für Justiz (2021) Infektionsschutzgesetz vom 20. Juli 2000 (BGBI. IS. 1045), das zuletzt durch Artikel 6 des Gesetzes vom 7. Mai 2021 (BGBI.IS. 850) geändert worden ist. https://www. gesetze-im-internet.de/ifsg/.Zugegriffen: 4. Aug 2021

3. Deutsche Gesellschaft für Krankenhaushygiene (2020) Konzept für Strategien zur Folgenminderung (Mitigierung) und zum Schutz gefährdeter Bevölkerungsgruppen (Protection) durch die COVID-19 Epidemie unter Berücksichtigung der Verhältnismäßigkeit. https://www. krankenhaushygiene.de/pdfdata/2020_03 22_DGKH_Mitteilung_Ausgangssperre_RKG_ Konzept.pdf.Zugegriffen:4. Aug. 2021

4. Walger $P$, Heininger $U$, Knuf $M$ et al (2020) Kinder und Jugendliche in der CoVid-19-Pandemie: Schulen und Kitas sollen wieder geöffnet werden Der Schutz von Lehrern, Erziehern, Betreuern und Eltern und die allgemeinen Hygieneregeln stehen dem nicht entgegen. https://www. krankenhaushygiene.de/pdfdata/2020_05_19 Stellungnahme_DGKH_Covid-19_Kinder.pdf.Zugegriffen: 4. Aug. 2021 (Stellungnahme der Deutschen Gesellschaft für Krankenhaushygiene (DGKH), der Deutschen Gesellschaft für Pädiatrische Infektiologie (DGPI), der Deutschen Akademie für Kinder- und Jugendmedizin (DAKJ), der Gesellschaft für Hygiene, Umweltmedizin und Präventivmedizin (GHUP) und des Berufsverbands der Kinder- und Jugendärzte in Deutschland (bvkj e. V.))

5. Simon A, Hübner J, Berner R, Huppertz HI, Walger $P(2020)$ Maßnahmen zur Aufrechterhaltung eines Regelbetriebs und zur Prävention von SARS-CoV2-Ausbrüchen in Einrichtungen der Kindertagesbetreuung oder Schulen unter Bedingungen der Pandemie und Kozirkulation weiterer Erreger von Atemwegserkrankungen. https://www.
krankenhaushygiene.de/ccUpload/upload/files/ 2020_08_03_Stellungnahme_DGKH_Paediater. pdf. Zugegriffen: 4. Aug. 2021 (Gemeinsame Stellungnahme der DGKH zusammen mit den Pädiatern unter dem Dach der DAKJ)

6. DGKH, DAKJ (2020) Auch unter hohen SARS-CoV-2 Infektionszahlen können Gemeinschaftseinrichtungen für Kinder und Jugendliche geöffnet bleiben, wenn die Hygieneregeln (AHA-L) bei zusätzlichen betrieblich- organisatorischen Maßnahmen eingehalten werden. https://www. krankenhaushygiene.de/pdfdata/2020_11_20_ Stellungnahme_DGKH_DAKJ_Kinder.pdf. Zugegriffen:4. Aug. 2021 (Gemeinsame Stellungnahme derDeutschen Gesellschaftfür Krankenhaushygiene e. V. und der Deutschen Akademie für Kinderund Jugendmedizin e. V.)

7. Hübner J, Simon A, Exner M et al (2021) Mit Ausweitung und Verbesserung der bestehenden $\mathrm{AHA}+\mathrm{L}-$ Regeln sowie ergänzenden Maßnahmen können Kitas und Schulen auch bei hohen Infektionszahlen offenbleiben Version. https:// www.krankenhaushygiene.de/pdfdata/DGKH DGPI\%20Empfehlung_18_01_2021.pdf. Zugegriffen: 4. Aug. 2021 (Aktualisierte Stellungnahme der Deutschen Gesellschaft für Pädiatrische Infektiologie (DGPI) und der Deutschen Gesellschaft für Krankenhaushygiene (DGKH) zur Rolle von Schulen und Kindertagesstätten in der COVID-19 Pandemie)

8. Hübner J, Simon A, Huppertz HI, Walger P, Berner R (2021) Aktualisierte Stellungnahme der Deutschen Gesellschaft für Pädiatrische Infektiologie (DGPI) und der Deutschen Gesellschaft für Krankenhaushygiene (DGKH) zur Rolle von Schulen und KiTas in der COVID-19 Pandemie. https://www. krankenhaushygiene.de/pdfdata/2021_01_04_ DGKH_PGPI_Stellungnahme.pdf. Zugegriffen: 4 . Aug. 2021

9. Walger P, Huppertz I, Hübner J, Simon A, Exner M, Berner R (2021) Kinder in der COVID-19 Pandemie. https://www.krankenhaushygiene.de/ pdfdata/2021 0205 DGPI DGKH zu Kindern COVID19.pdf. Zugegriffen: 4. Aug. 2021 (Deutsche Gesellschaft für Pädiatrische Infektiologie (DGPI)und Deutsche Gesellschaft für Krankenhaushygiene (DGKH))

10. Heimann T, Ewert J, Metzner F, Sigmund F, Jud A, Pawils S (2021) Medizinischer Kinderschutz während des Corona-Lockdowns. Vergleichende Befunde der Kinderschutzfälle aus Kliniken und Ambulanzen in Deutschland. Monatsschr Kinderheilkd 169:346-352

11. Stadt Frankfurt am Main (2021) Hygiene und Ausbruchsmanagement in der Corona-Pandemie I Krankenhäuser, Altenpflegeheime, soziale Einrichtungen, Schulen und Kitas (Berichtszeitraum Frühjahr bis Spätsommer 2020). ISBN 978-3941782-27-3

12. Stadt Frankfurt am Main (2021) Hygiene und Ausbruchsmanagement in der Corona-Pandemie II Krankenhäuser, Altenpflegeheime, soziale Einrichtungen, Schulen und Kitas (Berichtszeitraum Oktober bis Dezember 2020). ISBN 978-3-94178228-0

13. Horacek U, Auer I, Thaiss H (2021) Lebenswelten Kitas und Schulen - Herausforderungen für die Gesundheitsämter in der Pandemie. Bundesgesundheitsblatt Gesundheitsforschung Gesundheitsschutz 64(4):463-471. https://doi. org/10.1007/s00103-021-03304-1

14. Kompetenznetz Public Health COVID-19 (2020) Maßnahmen zur SARS-CoV-2-Infektionseindämmung in Kitas - Balanceakt zwischen Transmis- 
sion und kindlichen Entwicklungsbedürfnissen. https://www.public-health-covid19.de/images/ 2020/Ergebnisse/Handreichung_Kitas_2006115 V1.pdf.Zugegriffen: 4. Aug. 2021

15. Wegner RE (2005) Aufgaben des ÖGD im Rahmen der Kinder- und Jugendgesundheit. Bundesgesundheitsblatt Gesundheitsforschung Gesundheitsschutz 48:1103-1110

16. Gesundheitsministerkonferenz (2018) Leitbild für einen modernen öffentlichen Gesundheitsdienst (ÖGD) - Der ÖGD: Public Health vor Ort. https://bzoeg.de/aktuelles-leser/GMK-91Leitbild-OeGD.html. Zugegriffen: 4. Aug. 2021

17. RobertKoch-Institut(2021)SurvStat@RKI.Abfrage der Meldedaten nach Infektionsschutzgesetz (IfSG) über das Web. https://www.rki.de/DE/ Content/Infekt/SurvStat/survstat node.html. Zugegriffen:4.Aug. 2021

18. Robert Koch-Institut (2020) Präventionsmaßnahmen in Schulen während der COVID-19-Pandemie. https://www.rki.de/DE/Content/InfAZ/N/ Neuartiges_Coronavirus/Praevention-Schulen. pdf?_blob=publicationFile. Zugegriffen: 4 . Aug. 2021 (Empfehlungen des Robert Koch-Instituts für Schulen)

19. Loeffelholz MJ, Tang Y-W (2020) Laboratory diagnosis of emerging human coronavirus infections - the state of the art. Emerg Microbes Infect 9:747-756

20. Roche (2021) Produktinformationen Roche SARSCoV-2 Rapid Antigen Laientest. https://www. roche.de/patienten-betroffene/informationenzu-krankheiten/covid-19/sars-cov-2-rapidantigen-test-patienten-n/. Zugegriffen: 4. Aug. 2021

21. Heudorf U, Steul K, Walczok A, Gottschalk R (2021) Kinder und COVID-19: Kontaktpersonen-Surveillance in Frankfurter Kitas und Schulen (August bis Dezember 2020). Monatsschr Kinderheilkd 169:322-334. https://doi.org/10.1007/s00112021-01134-8

22. Heudorf U, Gottschalk R (2021) SARS-CoV-2 und die Schulen - Was sagen die Daten? Hess Arztebl 82:358-361

23. Berger U, Fritz C, Kauermann G (2021) Schulschließungen oder Schulöffnung mit Testpflicht? Epidemiologisch-statistische Aspekte sprechen für Schulöffnungen mit verpflichtenden Tests. CODAG Bericht, Bd. 14

24. Armann JP, Diffloth N, Simon A et al (2020) Hospitalisierungen von Kindern und Jugendlichen mit COVID-19. Erste Ergebnisse eines deutschlandweiten Surveys der Deutschen Gesellschaft für Pädiatrische Infektiologie. Dtsch Ärztebl 117(21):373-374

25. Streng A, Hartmann K, Armann J, Berner R, Liese JG (2020) COVID-19 bei hospitalisierten Kindern und Jugendlichen. Ein systematischer Review zu publizierten Fallserien (Stand 31.03.2020) und erste Daten aus Deutschland. Monatsschr Kinderheilkd. https://doi.org/10.1007/s00112020-00919-7

26. Berner $R$, Walger $P$, Simon A et al (2021) Stellungnahme von DGPI und DGKH zu Hospitalisierung und Sterblichkeit von COVID19 bei Kindern in Deutschland. https://www. krankenhaushygiene.de/pdfdata/presse/202104-21-Mortalitaet-Kinder.pdf. Zugegriffen: 4. Aug. 2021

27. Choi SH, Kim HW, Kang JM, Kim DH, Cho EY (2020) Epidemiology and clinical features of coronavirus disease 2019 in children. Clin Exp Pediatr 63(4):125-132. https://doi.org/10.3345/ cep. 2020.00535
28. Ludvigsson JF (2020) Systematic review of COVID-19 in children shows milder cases and a better prognosis than adults. Acta Paediatr 109(6):1088-1095. https://doi.org/10.1111/apa. 15270

29. She J, Liu L, Liu W (2020) COVID-19 epidemic: disease characteristics in children. J Med Virol 92(7):747-754. https://doi.org/10.1002/jmv. 25807

30. Zimmermann P, Curtis N (2020) Coronavirus infections in children including COVID-19. Pediatr Infect Dis J 39(5):355-368

31. Heudorf U, Exner M (2008) Hygiene in Schulen. Altbekannte Probleme nach wie vor aktuell. Bundesgesundheitsblatt Gesundheitsforschung Gesundheitsschutz 51:1297-1303

32. Heudorf U, Neuhäusel T, Demircan Y, Leonhardt K Petrozziello S, Savas G (2020) Toilettenhygiene in Schulen - ein altes und immer noch aktuelles Thema. Ergebnisse einer Umfrage bei Schulleitungen und Schülern in Frankfurt am Main, 2018. Gesundheitswesen 82(4):345-353. https://doi. org/10.1055/a-0955-5542

33. Steul K, Heudorf U (2021) Hygiene in Schulen in der Corona-Pandemie - Erfahrungen mit Hygienebegehungen in Schulen in Frankfurt am Main im Sommer 2020 und weitere Überlegungen. Hyg Med 46(9):D77-D85

34. Huppertz HI, Berner R, Schepker R et al (2020) Verwendung von Masken bei Kindern zur Verhinderung der Infektion mit SARS-CoV-2. Monatssch Kinderheilkd. https://doi.org/10.1007/s00112020-01090-9

35. Heudorf U (2008) Raumlufthygienische Probleme in Schulen - Bringen Passivhausschulen die Lösung? Umweltmed Forsch Prax 13:219-226

36. Heudorf U, Neitzert V, Spark J (2009) Particulate matter and carbon dioxide in classrooms-the impact of cleaning and ventilation. Int J Hyg Environ Health 212:45-55

37. Hessisches Kultusministerium und Unfallkasse Hessen (2008) Frische Luft für frisches Denken. https://www.landkreis-pfaffenhofen.de/media/ 9581/frische_luft_fuer_frisches_denken.pdf.Zu gegriffen:4.Aug. 2021

38. Exner M, Walger $P$ et al (2020) Zum Einsatz von dezentralen mobilen Luftreinigungsgeräten im Rahmen der Prävention von COVID-19. https://www.krankenhaushygiene.de/ pdfdata/2020_09_03_DGKH_Stellungnahme Zum_Einsatz_von_dezentralen_Luftreinigern_ zur_Praevention.pdf. Zugegriffen: 4. Aug. 2021 (Stellungnahme der DGKH)

39. Umweltbundesamt (2020) Mobile Luftreiniger in Schulen: Nur im Ausnahmefall sinnvoll; Empfehlungen des Umweltbundesamtes zum Einsatz von mobilen Luftreinigern als lüftungsunterstützende Maßnahme bei SARS CoV-2 in Schulen. https://kultusministerium. hessen.de/sites/default/files/media/hkm/uba empfehlung mobile luftreiniger in schulen. pdf.Zugegriffen:4.Aug. 2021

40. Heudorf U, Voigt K, Eikmann Th, Exner M (2011) Hygiene in Schulen - auch eine wichtige Aufgabe des öffentlichen Gesundheitsdienstes. Gesundheitswesen 73:730-736

41. Hamburg (2020) Hamburgs Schülerinnen und Schüler infizierten sich außerhalb der Schule offensichtlich vier Mal so häufig wie in der Schule. https://www.hamburg. de/coronavirus/14644922/2020-11-19-bsbcoronadaten-schulen/. Zugegriffen: 4. Aug. 2021 (und https://www.tagesspiegel.de/wissen/ von-bildungsbehoerde-unterdrueckte-corona- studie-einzelne-person-loeste-masseninfektionan-hamburger-schule-aus/26753114.html)

42. Stein-Zamir C, Abramson N, Shoob H et al (2020) A large COVID-19 outbreak in a high school 10 days after schools' reopening, Israel, Maa 2020. Euro Surveill 25(29):2001352. https://doi.org/10.2807/ 1560-7917.ES.2020.25.29.2001352

43. Gläser-Zorn A, Berkovitch $E$, Jakobs $A$ et al (2020) COVID-19 an Kölner Schulen. Eine differenzierte Übersicht der Schulentscheidungen im Gesundheitsamt der Stadt Köln bis zum Ende des Schuljahres 2019/2020. Epidemiol Bull 42:3-6. https://doi.org/10.25646/7107

44. Marx AK (2021) Corona an Schulen in der Metropole Ruhr. https://www.rvr.ruhr/fileadmin/user upload/01_RVR_Home/03_Daten_Digitales/ Regionalstatistik/03_Publikationen/2021-02_ Regionalstatistik_Ruhr_Corona_an_Schulen_in der_Metropole_Ruhr.pdf. Zugegriffen: 4. Aug. 2021 (Regionalstatistik Ruhr)

45. Buda S, an der Heiden M, Altmann D, Diercke M, Hamouda O, Rexroth U (2020) Infektionsumfeld von erfassten COVID-19 Ausbrüchen in Deutschland. Epidemiol Bull 38:3-12. https://doi.org/10.25646/ 7093

46. Otte im Kampe E, Lehfeld A, Buda S, Buchholz U, Haas W (2020) Surveillance of COVID-19 school outbreaks, Germany, March to August 2020. Euro Surveill 25(38):2001645. https://doi.org/10.2807/ 1560-7917.ES.2020.25.38.2001645

47. Dressler A, Finci I, Wagner-Wiening C, Eichner M, Brockmann SO (2021) Epidemiological analysis of 3,219 COVID-19 outbreaks in the state of Baden-Wuerttemberg, Germany. Epidemiol Infect 149:e101. https://doi.org/10.1017/ S0950268821000911

48. Berger U, GaußJ, Kauermann G (2021) Das aktuelle Ausbruchs- und Infektionsgeschehen in Schulen und an Arbeitsplätzen. CODAG-Bericht Nr. 16. https://www.covid19.statistik.uni-muenchen.de/ pdfs/codag_bericht_16.pdf. Zugegriffen:4. Aug. 2021

49. Fontanet A, Tondeur L, Grant R et al (2021) SARSCoV-2 infection in schools in a northern French city: a retrospective serological cohort study in an area of high transmission, France, January to A pril 2020. Euro Surveill 26(15):2001695. https://doi.org/10. 2807/1560-7917.ES.2021.26.15.2001695

50. Danis K, Epaulard O, Bénet T et al (2020) Cluster of coronavirus disease 2019 (Covid-19) in the French Alps, 2020. Clin Infect Dis 71(15):825-832

51. Heavey L, Casey G, KellyC, KellyD, McDarby G (2020) No evidence of secondary transmission of COVID19 from children attending school in Ireland, 2020. Euro Surveill 25(21):2000903-32489179. https://doi.org/10.2807/1560-7917.ES.2020.25. 21.2000903

52. Yung CF, Kam KQ, Nadua KD et al (2021) Novel coronavirus 2019 transmission risk in educational settings. Clin Infect Dis 72(6):1055-1058. https:// doi.org/10.1093/cid/ciaa794

53. DubT, Erra E, Hagberg Let al (2020) Transmission of SARS-CoV-2 following exposure in school settings: experience from two Helsinki area exposure incidents. https://www.medrxiv.org/content/10. 1101/2020.07.20.20156018v1. Zugegriffen: 4. Aug. 2021

54. Macartney K, Quinn HE, Pillsbury AJ et al (2020) Transmission of SARS-CoV-2 in Australian educational settings: a prospective cohort study. Lancet Child Adolesc Health 4(11):807-816. https://doi.org/10.1016/S2352-4642(20)30251-0

55. Lopez AS, Hill M, Antezano J et al (2020) Transmission dynamics of COVID-19 outbreaks 
associated with child care facilities-Salt Lake City, Utah, April-July 2020. MMWR Morb Mortal Wkly Rep 69(37):1319-1323. https://doi.org/10.15585/ mmwr.mm6937e3

56. Yoon Y, Kim KR, Park H, Kim S, Kim YJ (2020) Stepwise school opening and an impact on the epidemiology of COVID-19 in the children.J Korean Med Sci 35(46):e414. https://doi.org/10.3346/ jkms.2020.35.e414

57. Ehrhardt J, Ekinci A, Krehl H et al (2020) Transmission of SARS-CoV-2 in children aged 0 to 19 years in childcare facilities and schools after their reopening in May 2020, Baden-Württemberg, Germany. Euro Surveill 25(36):2001587. https://doi.org/10. 2807/1560-7917.ES.2020.25.36.2001587

58. Larosa E, Djuric O, Cassinadri M et al (2020) Secondary transmission of COVID-19 in preschool and school settings in northern Italy after their reopening in September 2020: a population-based study. Euro Surveill 25(49):2001911. https://doi. org/10.2807/1560-7917.ES.2020.25.49.2001911

59. Brandal LT, Ofitserova TS, Meijerink $\mathrm{H}$ et al (2021) Minimal transmission of SARS-CoV-2 from paediatric COVID-19 cases in primary schools, Norway, August to November 2020. Euro Surveill 26(1):2002011. https://doi.org/10.2807/15607917.ES.2020.26.1.2002011

60. Heudorf U, Steul K, Walczok A, Gottschalk R (2020) COVID-19 in Schulen. Keine Pandemie-, Treiber“. Dtsch Arztebl 117(51-52):A-2505/B-2111

61. European Centre for Disease Prevention and Control (2020) COVID-19 in children and the role of school settings in COVID-19 transmission. https://www.ecdc.europa.eu/en/publicationsdata/children-and-school-settings-covid-19transmission.Zugegriffen:4. Aug. 2021

62. Schoeps A, Hoffmann D, Tamm C et al (2021) COVID-19-transmission in educational institutions August to December 2020, Rhineland-Palatinate, Germany: a study of index cases and close contact cohorts. medRxiv preprint. https://doi.org/10. 1101/2021.02.04.21250670

63. Ismail SA, Saliba V, Lopez Bernal J, Ramsay ME, Ladhani SN (2020) SARS-CoV-2 infection and transmission in educational settings: a prospective, cross-sectional analysis of infection clusters and outbreaks in England. Lancet Infect Dis. https:// doi.org/10.1016/S1473-3099(20)30882-3

64. Mensah AA, Sinnathamby M, Zaidi A et al (2021) SARS-CoV-2 infections in children following the full re-opening of schools and the impact of national lockdown: prospective, nationa observational cohort surveillance, July-December 2020, England. J Infect 82(4):67-74. https://doi. org/10.1016/j.jinf.2021.02.022

65. Ladhani SN, Baawuah F, Beckmann J et al (2021) SARS-CoV-2 infection and transmission in primary schools in England in June-December, 2020 (sKIDs): an active, prospective surveillance study. Lancet Child Adolesc Health 5(6):417-427. https:// doi.org/10.1016/S2352-4642(21)00061-4

66. Haapanen M, Renko M, Artama M, Kuitunen I (2021) The impact of the lockdown and the re-opening of schools and day cares on the epidemiology of SARS-CoV-2 and other respiratory infections in children-A nationwide register study in Finland. EClinicalMedicine 34:100807. https://doi.org/10. 1016/j.eclinm.2021.100807

67. Dinnes J, Deeks JJ, Berhane $S$ et al (2021) Rapid, point-of-care antigen and molecular-based tests for diagnosis of SARS-CoV-2 infection. Cochrane Database Syst Rev 3:CD13705. https://doi.org/10. 1002/14651858.CD013705.pub2
68. Hoehl S, Schenk B, Rudych O, Göttig S, Kohmer N, Karaca O, Toptan T, Ciesek S (2021) High-frequency self-testing by schoolteachers for Sars-Cov-2 using a rapid antigen test: results of the safe school Hesse study. Dtsch Arztebl Int 118:252-253. https://doi. org/10.3238/arztebl.m2021.0187

69. Bernar B, Strenger V, Zurl C, Kerbl R Bundesministerium Bildung, Wissenschaft und Forschung. Evaluierung des SARS-CoV-2-Screenings mittels anterior-nasalen Antigen-Selbsttests an österreichischen Schulen. Kalenderwoche 8. https://www.bmbwf.gv.at/dam/jcr:c5386ac9c35b-45d7-9c11-512f78c42051/NASTs_Bericht_ KW 8 FINAL 202103 13.pdf

70. Heudorf U, Gottschalk R (2021) Narrative und Angst statt Evidenz und Erfahrung. Hess Arztebl 82:555

71. Walger $P$, Simon $A$, Hübner J, Huppertz HI, Exner M, Berner R (2021) Kommentar der DGKH und der DGPI zu flächendeckenden Antigentests an Schulen: Was lernen wir aus den derzeitigen österreichischen Erfahrungen? https://www.krankenhaushygiene.de/pdfdata/ Kommentar\%20von\%20DGPI\%20und\%20DGKH \%20zu\%20Schnelltests\%20an\%20Schulen_\%C3 \%96sterrich.pdf.Zugegriffen:4. Aug. 2021

72. Hübner J, Simon A, Dötsch J et al (2021) Teststrategien zur COVID Diagnostik in Schulen. https://dgpi.de/wp-content/uploads/2021/02/ Stellungnahme-Schnelltests_final_logos_28_ 02_2021.pdf.Zugegriffen:4.Aug. 2021

73. Schmidt L (2021) Und was ist mit uns? Frankfurter Allgemeine Sonntagszeitung, Ausgabe 18, S.9

74. Galow L, Haag L, Kahre E et al (2021) Lower household transmission rates of SARS-CoV-2 from children compared to adults. J Infect. https://doi. org/10.1016/j.jinf.2021.04.022

75. Ravens-Sieverer U, Kaman A, Erhart M, Devine J, Schlacks R, Otto C (2021) Impact of the COVID19 pandemic on quality of life and mental health in children and adolescents in Germany. Eur Child Adolesc Psychiatry. https://doi.org/10.1007/ s00787-021-01726-5

76. Blankenburg J, Wekenborg MK, Reichert J et al (2021) Mental health of adolescents in the pandemic: long-COVID19 or long-pandemic syndrome? https://www.medrxiv.org/content/ 10.1101/2021.05.11.21257037v1.Zugegriffen: 4. Aug. 2021

77. Gottschalk R, Heudorf U (2020) Die Covid19-Pandemie - bisherige Erkenntnisse und Empfehlungen für das weitere Vorgehen. Hess Arztebl 81:551-552

78. Heudorf U, Gottschalk R (2020) Die Covid-19Pandemie in Frankfurt am Main: Was sagen die Daten? Hess Arztebl 81:548

79. Heudorf U (2020) COVID-19-Pandemie - Rationalität statt Regelungschaos tut not. (Editorial). Gesundheitswesen 82:941-943

80. Heudorf U, Exner M (2021) COVID-19 und der Öffentliche Gesundheitsdienst. Hyg Med 46(1-2):D10-D15

81. BMG (2020) Paktfür den öffentlichen Gesundheitsdienst.https://www.bundesgesundheitsministerium. de/fileadmin/Dateien/3_Downloads/O/OEGD/ Pakt_fuer_den_OEGD.pdf. Zugegriffen: 4. Aug. 2021 